\title{
Relevance for the Danube Region
}

DOI: 10.24989/ocg.v331.41

This section details the relevance for the Danube Region for those contributions that do not immediately relate to the Region. The following texts were provided by Robert Müller-Török und Alexander Prosser. 


\section{DIGITAL GOVERNMENT AS SERVICE DELIVERY FOR DIFFICULT TERRITORY A CASE STUDY OF BONIN ISLANDS}

\section{Hiroko Kudo}

The paper analyses the role of digital services in the development of regions which are either economically disadvantaged and/or not connected to the main axes of traffic with a special view of regions encompassing both regions that are economically advantaged and disadvantaged. The paper discusses research results from the indo-pacific region, however, these results directly translate into the Danube Region, where "old" economically advantaged and reform regions can be found. Here and there, the levelling of these economic and infrastructural differences is a key political topic. The paper describes how digital services, with a special view to smart city services, may contribute to this economic development process in the less advantaged regions.

The paper also stresses the relationship between "physical" infrastructure development and said digital services giving examples. The conclusions drawn are very similar to the conclusions by Tirziu/Vrabie and Schenk/Laue. Particularly the role of Business Intelligence and Internet of Things infrastructure is pointed out; the research results provide an interesting and stimulating analogy to the Danube Region. 


\section{THE SHOPPERS; VENUE SHOPPING, ASYLUM SHOPPING: A RESOLUTION IN EURODAC?}

\section{Catherine Odorige}

The topic of asylum seekers and the abuse of the right to asylum are stringent topics in the Danube Region. Asylum shopping and waves of migrants moving throughout the Danube Region towards wealthy places, such as Germany or Austria constitute a problem that threatens to undermine the political cohesion in the Danube Region. Also the internationalisation of migration and asylum control policy in the framework of venue shopping stringently applies to the Danube Region.

The paper presents EURODAC, an automated biometric identification allowing for instant and exact comparison of unique physiological features for individual's iris, face and finger print for law enforcement purposes of illegal migrants. EURODAC can therefore be a viable solution to detect and furthermore prevent asylum shopping throughout the Danube Region.

\section{DIGITALISATION VS. INFORMATIZATION: DIFFERENT APPROACHES TO GOVERNANCE TRANSFORMATION}

\section{Alois Paulin}

The paper analyses the relevance of the informatisation for the public sector in view of the " 4.0 " debate, that is the steps from mechanisation to automation to digitisation to informatisation. The discussion originated in the private - mainly manufacturing - sector, but also applies to smart cities and other domains of public ICT (see the paper of Prosser in this volume).

The paper then stringently argues how the step from digitisation to informatisation transforms realworld governance structures. This is an effect that can be observed in the Danube Region (see for example the paper of Nemeslaki); on the other hand, failure to change governance structures may stop the digitisation, for a negative example from Baden-Württemberg, see the paper of Schenk/Giesbrecht.

The paper then introduces the concept of "governance informatisation" utilising the technologies to overhaul governance as such and to adapt it to the present-day infrastructure. This is actually one of the "opportunities" cited by Grecu et al. in their paper. It may provide stimulus to overcome the impasse in the case described by Schenk/Giesbrecht. 


\section{BIG DATA AND ALGORITHMS IN THE PUBLIC SECTOR AND THEIR IMPACT ON THE TRANSPARENCY OF DECISION-MAKING}

\section{Gergely László Szőke}

The paper provides a stringent discussion on how real-time, transaction data-based business intelligence may transform a public sector organisation. This transformational aspect alone makes it highly relevant to the Danube Region (the paper is from a Hungarian author, yet deals with the topics on a general level). The paper actually deals with a similar domain as the contribution by Petrov/Petrov from Moldova describing and analysing very similar effects in the Moldovian context.

Of course, the transparency is limited mainly by the General Data Protection Regulation, which is stringently outlined by the paper. Here the paper may be read in conjunction with the contribution of Orbán analysing the limitations of open government data in Hungary.

\section{CYBERSECURITY IN THE EUROPEAN UNION}

\section{Andreas Düll, Anja Schoch and Matthias Straub}

The contribution describes the EU framework for cyber defence and resilience. The description is necessarily on a general, EU-wide, level, nevertheless the Danube Region is particularly prone to cyber-attacks, not only due to the small scale of most of the countries, which prevent utilisation of scale effects in cyber-defence measures, but also due to the specific risk exposure of the region. In this connection, this paper is related to research presented in this volume by Szádeczky describing the corresponding initiatives and frameworks in Hungary.

However, the paper concludes that "[t]he Commission's strategy does not contain any comprehensible criteria that could shed light on which instruments should be used", which is particularly disappointing for the countries of the Danube Region, which would benefit from a standardised EU-wide framework. The work of the European Cybercrime Centre is analysed and here opportunities for the (on average) smaller countries of the Danube Region for utilising scale effects arise. Such work can provide valuable input, for instance, for the cyber-defence activities at one of the conference host institutions, the University of Public Service. 


\section{IMPROVING DISTRIBUTED VULNERABILITY ASSESSMENT MODEL OF CYBERSECURITY}

\section{Kálmán Hadarics and Ferenc Leitold}

The contribution analyses the Vulnerability Assessment Model in cyber-security; it links up with the papers by Düll et al. and Szádeczky in this volume. It provides a modelling framework for the elements of cyber-defence; a particular merit is the broad range of cyber-attack types. This modelling framework could be a valuable input to the cyber defence education and research centre that is currently being built up at the host institution of the conference. It reflects the need for a scalable, effective cyber defence system for the - on average - small and medium-sized countries in the region.

Of particular interest is the inclusion of human factors in the model. The relevance for the Danube Region is the identification of needs for capacity building in the pertinent fields and can provide research-based input in programme definitions of institutions, such as EUSDR PA10 and similar frameworks.

\section{OTT REGULATION A WAY OF COMBATING CYBERCRIMES}

\section{Veronica Mocanu}

The paper deals with Over-the-Top (OTT) services, that is the distribution of television or radio over the Internet without the control of a network operator. Today, this mainly concerns international players, such as youtube, HBO or Netflix; however, in the future as the technology will mature, also local/regional service providers are almost bound to emerge. This is particularly true for services in local language. This may happen in the framework of local subsidiaries of international organisations or genuinely regional players. Due to ethnic minorities in the Danube Region, such local-language services will automatically generate considerable cross-border traffic. All the regulatory issues brought up by the paper apply.

The paper analyses a number of risks for OTT services that equally apply to regional service providers. A solution in this regard may be provided by the regulatory framework of the European Union, which is presented in the paper. Due to the territorial, legal and language fragmentation that directly affects OTT services, such regulatory framework is immensely useful for the Danube Region. 


\section{EGOVERNMENT AS AN ELEMENT OF THE RIGHT TO GOOD ADMINISTRATION}

\section{Justyna Matusiak and Marcin Princ}

The contribution "eGovernment as an element of the right to good administration" by Justyna Matusiak and Marcin Princ establishs a link between eGovernment and the EU Charter of Fundamental Rights. When we have a look on e.g. the current processing times of the German Administrative Courts, which are ipso facto dead-locked by migration and asylum cases, it appears evident, that in times of increased absolute administration process figures the whole administrative process must be streamlined, namely by means of eGovernment. The issue is very relevant for the Danube Strategy Countries, simply because migration and asylum issues are tied to the famous "Balkan Route", which goes along the Danube from Moldova and Bulgaria to Germany. Poland is, much to our dismay, not within the Danube Strategy, but it belongs both to CEE and to the Visegrad Group, hence parallels between Polish and Danube administration may be drawn. The main finding of the paper, that "eGovernment regnorum fundamentum", is very applicable in all the Danube Strategy Countries.

\section{ECOHESION: HOW TO MEASURE THE MAIN DRIVERS OF ADMINISTRATIVE BURDEN REDUCTION}

\section{Tamás Laposa}

The same topic is covered and, more than that, dealt with at a more detailled level by "ECOHESION: HOW TO MEASURE THE MAIN DRIVERS OF ADMINISTRATIVE BURDEN REDUCTION" by Tamás Laposa. His eCohesion is derived from Regulation 1303/2013 which defines Electronic Data Interchange, Interoperability and the Once-only-principle as the fundaments of applied eGovernment. So whilst Justyna Matusiak and Marcin Princ answer the "Why", Tamás Laposa answers the "How". Namely interoperability is, in a Danube Region where no large domestic state exists, but borders every 50 kilometers, the name of the game. Without eCohesion the Danube Region will be as divided as Germany before the "Deutscher Zollverein", i.e. a totally divided country with independent administrations and massive burdens for citizens, businesses and also administrations. Laposa also provides evidence for cost benefits, an issue very relevant to most of the Danube Region Countries. 


\section{GLOBAL IDENTITY MANAGEMENT FOR INDIVIDUALS? \\ THE RIGHT TO BE FORGOTTEN AND ISSUES OF EXTRATERRITORIALITY}

\section{Petra Lea Láncos}

Petra Láncos provides a different topic, which is strongly relevant for all EU Member States and for the Candidate States of the Danube Region. Her contribution "Global identity management for individuals? The right to be forgotten and issues of extraterritoriality" deals with the EU General Data Protection Regulation, which will enter into force shortly after the conference, on May 25th, 2018. Due to the trend of moving sensitive applications to smaller countries with a more favorable jurisdiction, the topic is very relevant for the Danube Strategy Countries. Enterprises like gmx.de or Facebook can easily switch server locations and try to avoid e.g. a Legislation and Jurisdiction in Spain by moving to Moldova or Romania. The solution pointed out by the French Constitutional Court seems very applicable in this context.

\section{REVISITING OPEN DATA RESEARCH THROUGH THE LENS OF THE DATA VALUE CHAIN}

\section{Csaba Csáki and Andrea Kő}

The contribution "REVISITING OPEN DATA RESEARCH THROUGH THE LENS OF THE DATA VALUE CHAIN" deals with the topic of Open Data in General and Open Government Data in particular. In the traditional western-european countries it is not known that many Open Data laws and Freedom of Information Acts were issued after the fall of the Iron Curtain, whilst developed western states like e.g. Bavaria or Baden-Württemberg got such legislation either decades later or not yet. So it seems more than valuable to gain from the vast experience the two authors have. The value chain seems to be a very interesting progress in that context and should be widely shared. 


\section{RESEARCHERS AS MEDIATORS BETWEEN POLICYMAKERS AND PRACTITIONERS - DO THEY HAVE THE NECESSARY SKILLS?}

\section{Adriana Zaiţ}

Her contribution "Researchers as mediators between policymakers and practitioners - do they have the necessary skills?" questions the self-perception of scientists, a topic very appropriate at an international conference of researchers. Especially nowadays, where scientists are appointed ipso facto as referees on so-called "fake news" and asked questions politicians can either not answer or are not believed if they try to answer, this issue becomes very important. Her research shows that there is, especially in Romania where the study took place, room for improvement of skills of researchers. We believe sincerely that her results are applicable all over the Danube Region.

\section{THE PERMANENT CAMPAIGN IN SOCIAL MEDIA: A CASE STUDY OF POLAND}

\section{Dorota Domalewska}

"War is the father of all things" of ancient Heraclitus could be the first thought when Dorota Domalewska from the War Studies University of Poland presents us with her contribution "THE PERMANENT CAMPAIGN IN SOCIAL MEDIA: A CASE STUDY OF POLAND”. Based on a a study in her native Poland she presents us with impressing findings which could change our perception of politics and political campaigning. The election campaigning seems to become a permanent institution, not restricted to the few months before elections any more. Her insights into politicians using Twitter are highly relevant for the Danube Region Countries, especially those with a higher level of political discourse or a higher percentage of active politicians. And even the sitting US President can probably be better understood after having read this study. 